\title{
Q-angle, Pelvic width, and Intercondylar notch width as predictors of knee injuries in women soccer players in South Africa
}

\author{
Mohamed $\mathrm{EE}^{1}$, *Useh $\mathrm{U}^{2}$, Mtshali $\mathrm{BF}^{1}$
}

\author{
1. Physiotherapy Department, University of Limpopo, Medunsa Campus, P.O. 239, Medunsa 204, \\ Pretoria, South Africa \\ 2. School of Environmental and Health Sciences, North West University, Mafikeng Campus, Mmabatho, \\ North West, South Africa
}

\begin{abstract}
Objective: To investigate the association between the three anatomical factors of Q-angle (QA), pelvic width (PW) and Intercondylar notch width (INW) and knee injuries among the U-23 female soccer players of South Africa

Methods: The study is a case-control prospective study design. Twenty four U-23 women soccer players of the South African team were purposively chosen to participate in this study. Participants were divided into two groups: group1 (Case) was those with knee injuries, while those without injuries were in group-2 (Control). PW and INW were measured after Xrays of the hip were taken while the QA was measured manually with the goniomenter. Association between anatomical factors and knee injuries were tested with ANOVA.

Results: Q-angle ranged from $14^{0}$ to $18^{\circ}$ for both injured and non injured groups. PW was between $24-29 \mathrm{~cm}$ for both injured and non injured groups. INW was between $1.3 \mathrm{~mm}$ and $2.8 \mathrm{~mm}$ for the right and between $1.4 \mathrm{~mm}$ and $2.5 \mathrm{~mm}$ for the left notch for the injured group, while INW for the right and left of the non injured group were between $1.7 \mathrm{~mm}$ to $2.1 \mathrm{~mm}$ and $1.8 \mathrm{~mm}$ to $2.1 \mathrm{~mm}$, respectively No significant association between knee injuries and each of the anatomical factors was found QA ( $p=0.74), P W(p=0.34)$, INW (right and left respectively) ( $p=0.142 \& p=0.089)$.

Conclusion: The three anatomical factors of QA, PW and INW could not be used to predict knee injuries amongst the U23 female players in South Africa.
\end{abstract}

Keywords: Pelvic width; Q-Angle; Intercondylar Notch Width; Female Soccer; Knee Injuries African Health Sciences 2012; 12(2): 174 - 180 http://dx.doi.org/10.4314/ahs.v12i2.15

\section{Introduction}

Physical activity is very important for all human beings and the benefits are well-documented for both genders ${ }^{1,2}$ The level of physical activity will differ in frequency, intensity, and duration depending on gender, age, and type of physical activity. Sport is defined as physical activity involving a structured competitive situation governed by rules ${ }^{3}$.Soccer is one such example and is considered one of the most popular sport with women making up to $22 \%$ of world's soccer player ${ }^{4}$. According to Strong et $\mathrm{al}^{1}$ numerous benefits of sport to women have been documented. Amongst these are lifestyle improvements, low teenage pregnancy rate, low drug

*Correspondence author:
Professor Ushotanefe Useh
School of Environmental and Health Sciences
North West University, Mafikeng Campus
Mmabatho, North West
South Africa
Email:22839968@,nwu.ac.za
ushotanefe.useh@nwu.ac.za

and alcohol use and abuse, higher graduation rate, improved self-esteem and body image, increased bone mass, cardiovascular function and weight control ${ }^{1}$.

Over the last twenty years, women soccer has experienced tremendous improvement and growth with a series of events organized by FIFA and the Olympics. Examples of these are; the first women's football cup in China in 1991, Olympic Games in 1994, U-19/ U-23 World Championship in $2002^{5}$. Most countries including South Africa have national female teams and a local league. There are currently more than 300 women's soccer clubs registered by the South African Football Association (SAFA) and a pool of about 50000 players. In Africa the first women's soccer tournament was held in $1995^{6}$ Generally, injuries abound in soccer and increasing incidences of injuries have been reported in female soccer. The most common injuries among female athletes are knee injuries, especially injury to the anterior cruciate ligament (ACL) ${ }^{7}$ Adolescent females suffer a disproportionate number of knee and 
anterior cruciate ligament (ACL) injuries compared to adolescent males. McAlindon ${ }^{8}$ found that female athletes have four to ten times more ACL injuries than male athletes. This was further reiterated by Ireland and Otto ${ }^{9}$ who stated that female athletes have an increased rate of ACL injuries and patelofemoral disorders compared with their male counterparts. Knee injuries in soccer also occur without contact from another person and most often occur while the player is participating in the training programme. These training programmes include deceleration, twisting, jumping, and other sport specific maneuvers ${ }^{10}$. There have been many studies comparing injury rates between male and female players $^{8,11,12}$. It was found that women soccer players sustain more knee injuries than their male counterparts ${ }^{11}$ with ACL, the medial collateral ligament (MCL) and acute injuries to the menisci as the most common ${ }^{13}$.

'More information on ACL injuries compared to other knee injuries have been documented ${ }^{13-15}$. ACL provides $85 \%$ of the total restraining force to anterior translation of the tibia ${ }^{14}$.Injuries to the ACL usually occur during a sudden deceleration, as it typically is a noncontact injury ${ }^{14}$. An ACL tear is a common injury in all sports. Epidemiological studies of the ACL injury among female athletes revealed that female soccer players sustained 2.29 times more ACL injuries than male soccer players ${ }^{16}$. Giza et al ${ }^{17}$ analyzed 173 injuries that occurred during the 20012002 seasons of the Women's United Soccer Association (WUSA) and found that the most common site for injuries was the knee with $(31.8 \%)$ and ACL injuries accounted for $4.8 \%$. The reasons for the higher rate of knee injuries in women are not clear. Some theories have implicated internal factors such as differences in the anatomical configuration between genders, knee ligament, ligament laxity and muscle strength ${ }^{18}$ and extern al factors, such as conditioning, type of training and the development of muscle coordination ${ }^{19}$.

The higher QA in females is reported to influence knee injuries in female athletes ${ }^{20}$. Horton and Hall ${ }^{21}$, reports a mean QA of $15.8 \pm 4.5$ degrees for women and $11.2 \pm 3.0$ degrees for men. Increase in QA might contribute to an increase in the contact pressure applied to the patellofemoral join $\mathrm{t}^{22}$.A valgus knee and a pronated foot are often implicated in knee injuries ${ }^{23}$. A potential factor in knee injury is intercondylar notch configuration ${ }^{14}$.Studies have shown that players with smaller intercondylar notch dimensions are at greater risk for ACL injury because it accommodates the $\mathrm{ACL}^{14,24-25}$. On the contrary a African Health Sciences Vol 12 No 2 June 2012 few studies found no relationship between the anatomical factors and predisposition to knee injuries ${ }^{26,27}$. There is however, limited empirical information on the association between anatomical factors and knee injuries amongst female soccer players in South Africa. This study will attempt to establish the association between knee injuries and each of the following anatomical factors: QA, PW and INW.

\section{Methods}

The design for this study is a case-control prospective study design. All the 24 U-23 national female soccer players of South Africa were participants in this study. They were divided into two groups, according to the presence or absence of knee injuries. Those with injury were in group-1 (Case) while those without injuries were in group-2 (Control).

\section{Data collection sheet, X-ray, and Goniometer were used to collect data}

The data collection sheet was divided into four sections. The first section was for demographic data (Name, age, weight, height and position on the field, current club name, seasons played for the current club, and other clubs played for (if any)). The second section was for history of injury (if any). The third section sought information on management of the injury. The last section required information on other injuries.

\section{Procedure for data collection}

The objectives of this study were presented to the administrative section of the U-23 women soccer project of SAFA in March 2008 prior to obtaining permission to conduct this study. Approval to conduct the study was granted after the presentation. Two week later, participants were taken to Dr George Mukhari (DGM) hospital where all radiographs and anatomical measurements were taken.

\section{Measurement of intercondylar noch width (INW)}

Plain X-rays of both lower limbs were taken using Shimadzu, RAD speed Safire machine. The first Xray used a conventional film for both pelvis and knees, from the anterior superior iliac spine to the patella of both lower limbs with participants in standing position. While the second one used digital film for the intercondylar notch with participants in 'tunnel view' position (which is semi prone with knee flexed 
$>80^{\circ}$ ). Machine measurements were (66-68KV, 25 MAS, $0.12 \mathrm{Sec}$ ) for both exposures. The intercondylar noch width was then measured as seen in figure 1 as reported by Shelbourne et $\mathrm{a}^{28}$. The INW is the distance between. Point A and B)

Figure 1: Measurement of INW according to Shelbourne et $\mathrm{al}^{28}$

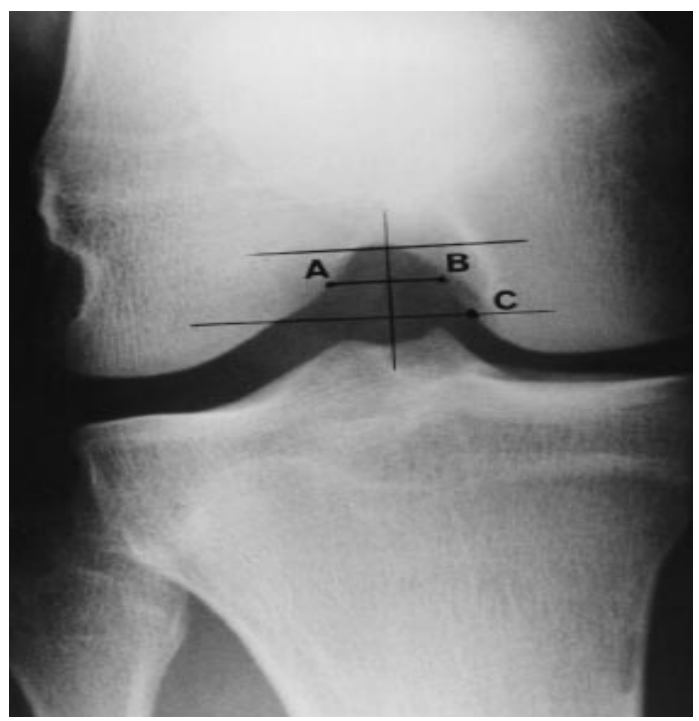

\section{Measurement of Q Angle}

The QA measurements were taken manually with the universal goniometer as described by Emami et $\mathrm{al}^{29}$ and Smith et $\mathrm{al}^{30}$. All measurements were taking with participants in standing with knees exposed in full extension (figure 2). The proximal arm of the goniometer was aligned to the anterior superior iliac spine, the axis at the midpoint of the patella, while the distal arm was aligned to the tibial tubercle. The intrarater reliability of the goniometer measurements was 0.90 .

Figure 2: Measurement of Q-Angle according to Smith, Hunt Donell ${ }^{30}$

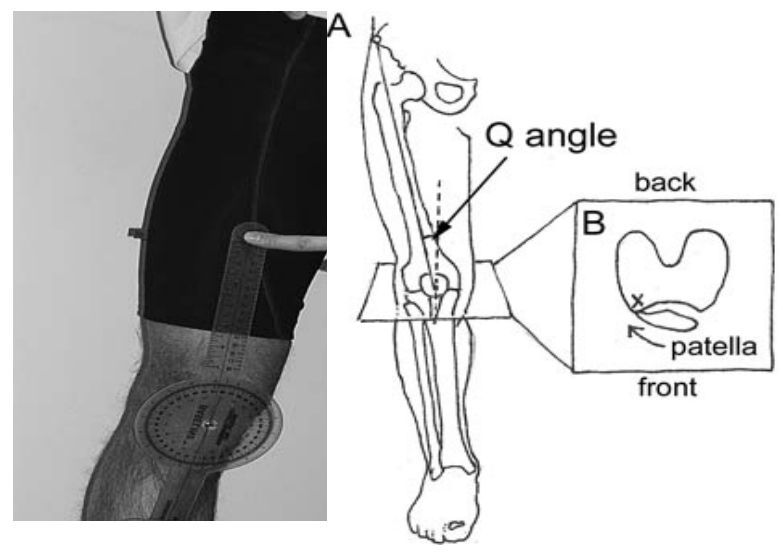

176

\section{Measurement of pelvic width}

Tape measure was used to measure the distance between the left and the right anterior superior iliac spine and the width recorded in $\mathrm{cm}$.

\section{Pilot study}

The data collection sheet was piloted on four players of the non-professional Garankuwa women soccer club side to test for clarity, ambiguity and time to complete.

\section{Ethical consideration}

This study was approved by the Research, Ethics and Publications Committee of the Faculty of Medicine, University of Limpopo (Medunsa Campus), DGM Hospital and the administration section of the women soccer project of SAFA. Informed consent was obtained from participants using the University of Limpopo (Medunsa Campus) consent form prior to the $\mathrm{X}$-ray procedures.

Participants were also provided with the information sheet which included the aims and objectives of the study and were given the opportunity to ask questions. It was made clear that the participation in this study was voluntary and that they may withdraw from it at any time without giving reasons.

\section{Interpretation of the $\mathrm{X}$-rays}

A radiologist at the department of radiology at DGM Hospital interpreted all the X-rays in this study.

\section{Data analysis}

The data emanating from this study was analyzed with a statistical package of social sciences version 17. Descriptive statistics of means and standard deviation (SD), percentages were used to describe the demographic information of the participants while tables were used to present data. Inferential statistics of ANOVA was used test the relationship between the variables evaluated. Each was categorized based on the concept or construct that they represented between the groups. The level of significance was set at 0.05 .

\section{Results}

\section{Description of the participants}

The participants were between 17 and 22 years, with a mean age of 18.92 years \pm 1.17 (SD), body weight of between $55 \mathrm{~kg}$ and $63 \mathrm{~kg}$ and a mean and SD of $58.5 \mathrm{~kg} \pm 2.28$, and height of between of 157 and $172 \mathrm{~cm}$ and a mean and SD of $165 \mathrm{~cm} \pm 4.46 \mathrm{~cm}$. Summary of measurements is presented in table 2 . 
They were no mean differences between the women who have sustained knee injuries (mean $=18.9$ and $\mathrm{SD}=1.19$ ) and who have not sustained knee injuries
$($ mean $=19.0$ and SD $=1.49)$. Both have the same median of 19 and a significant value of $\mathrm{p}=0.0023$ as shown in table 1.

Table 1: Characteristics of participants

\begin{tabular}{lccccccc}
\hline & \multicolumn{3}{c}{ Injured } & & \multicolumn{3}{c}{ Without knee injuries } \\
\hline Characteristics & Mean & Median & SD & & Mean & Median & SD \\
\cline { 2 - 4 } \cline { 7 - 8 } Age & 18.9 & 19 & 1.19 & & 19.0 & 19 & 1.49 \\
Position & 3.6 & 4 & 1.95 & & 3.36 & 4 & 4 \\
\hline
\end{tabular}

P-value $=0.0023$

Regarding playing position, a large number of respondents who were not injured were midfielder, $10(71.4 \%)$, followed by defenders, 3 (21.1\%). Large participants who sustained knee injury were forwards players 4(40\%), $2(20 \%)$ were goal keepers, defenders and midfielder. Please note that: Contact injuries are those sustained during tackles while non-contact are those sustained without contact/ tackle

About $6(60 \%)$ of the incidents of knee injuries were due to contact injuries and the rest of knee injuries were due to non contact. Four (40\%) of the injured players continued playing despite injury. Four participants did not respond to this question as indicated in table 2.

Table 2: Cause of Knee injuries

\begin{tabular}{lll}
\hline $\begin{array}{l}\text { Cause of Injury } \\
\text { Knee contact }\end{array}$ & No. & \% \\
\hline Yes & 6 & 60 \\
No & 4 & 40 \\
Continue to play & & \\
Yes & 4 & 40 \\
No & 2 & 20 \\
No response & 4 & 40 \\
\hline
\end{tabular}

\section{Q-angle}

The values of the Q-angles were scattered between $14^{0}$ up to $18^{0}$ for both injured and non injured groups, while $5(50 \%)$ of the injured group have the same Qangle of value $16^{\circ}$ and $5(35.7 \%)$ of the non injured group has $Q$ angles of $15^{\circ}$ also $5(35.7)$ of the non injured group have the same $\mathrm{Q}$-angle values of $16^{0}$. (table3).

\section{Pelvic width}

The different values of pelvic width of the players started from $24 \mathrm{~cm}$ up to $29 \mathrm{~cm}$ for both injured and non injured groups. The most standard value was shown in between 26 and 26.9 (table 3).

\section{Intercondylar notch}

Injured group recorded Intercondylar notch values of between $1.3 \mathrm{~mm}$ to $2.8 \mathrm{~mm}$ for the sright and $1.4 \mathrm{~mm}$ to $2.5 \mathrm{~mm}$ for the left. While the non injured recorded measurement of between $1.7 \mathrm{~mm}$ to $2.1 \mathrm{~mm}$ for the right and $1.8 \mathrm{~mm}$ to $2.1 \mathrm{~mm}$ for the left (table 3 )

Table 3: Summary of the measurements of the anatomical factors

\begin{tabular}{|c|c|c|c|c|c|c|c|c|}
\hline \multirow[t]{3}{*}{ Anatomical Factors } & & \multirow[t]{3}{*}{$\mathrm{N}$} & \multirow[t]{3}{*}{ Mean } & \multirow[t]{3}{*}{ Std. Deviation } & \multicolumn{2}{|c|}{$\begin{array}{l}95 \% \text { Confidence } \\
\text { Interval for Mean }\end{array}$} & \multirow[t]{3}{*}{$\begin{array}{l}\text { Mini- } \\
\text { mum }\end{array}$} & \multirow[t]{3}{*}{$\begin{array}{l}\text { Maxi- } \\
\text { mum }\end{array}$} \\
\hline & \multirow[t]{2}{*}{ Groups } & & & & Lower & Upper & & \\
\hline & & & & & Bound & Bound & & \\
\hline \multirow[t]{4}{*}{ Q-Angle/ ${ }^{\circ}$} & 0 & 14 & 16.0714 & 1.07161 & 15.4527 & 16.6902 & 15.00 & 18.00 \\
\hline & 1 & 4 & 16.2500 & 1.25831 & 14.2478 & 18.2522 & 15.00 & 18.00 \\
\hline & 2 & 6 & 15.7500 & .98742 & 14.7138 & 16.7862 & 14.00 & 17.00 \\
\hline & Total & 24 & & & & & & \\
\hline \multirow[t]{4}{*}{ Pelvic Width/cm } & 0 & 14 & 27.2286 & 1.28148 & 26.4887 & 27.9685 & 25.00 & 29.00 \\
\hline & 1 & 4 & 26.5000 & 1.26754 & 24.4831 & 28.5169 & 25.00 & 27.60 \\
\hline & 2 & 6 & 26.4500 & 1.01931 & 25.3803 & 27.5197 & 24.50 & 27.50 \\
\hline & Total & 24 & & & & & & \\
\hline \multirow[t]{4}{*}{ INW-Right/mm } & 0 & 14 & 1.8857 & .14601 & 1.8014 & 1.9700 & 1.70 & 2.10 \\
\hline & 1 & 4 & 1.7750 & .33040 & 1.2493 & 2.3007 & 1.30 & 2.00 \\
\hline & 2 & 6 & 2.1000 & .40988 & 1.6699 & 2.5301 & 1.60 & 2.80 \\
\hline & Total & 24 & & & & & & \\
\hline \multirow[t]{3}{*}{ INW-Left/mm } & 0 & 14 & 1.9286 & .12044 & 1.8590 & 1.9981 & 1.80 & 2.10 \\
\hline & 1 & 4 & 1.8500 & .31091 & 1.3553 & 2.3447 & 1.40 & 2.10 \\
\hline & 2 & 6 & 2.1167 & .25626 & 1.8477 & 2.3856 & 1.80 & 2.50 \\
\hline
\end{tabular}


Group $0=$ Players without knee injuries

Group $1=$ Players with knee injuries without contact

Group 2 = Players with knee injuries with contact

Table 4: The relationship between anatomical factors and knee injuries

\begin{tabular}{|c|c|c|c|c|c|c|}
\hline Anatomical factors & & $\begin{array}{l}\text { Sum of } \\
\text { Squares }\end{array}$ & $\mathrm{DF}$ & $\begin{array}{l}\text { Mean } \\
\text { Square }\end{array}$ & $\mathbf{F}$ & Sig. \\
\hline \multirow[t]{2}{*}{ Q-angle } & Between Groups & .686 & 2 & .343 & .293 & .749 \\
\hline & Within Groups & 24.554 & 21 & 1.169 & & \\
\hline \multirow{2}{*}{ P-width } & Between Groups & 3.363 & 2 & 1.681 & 1.126 & .343 \\
\hline & Within Groups & 31.364 & 21 & 1.494 & & \\
\hline \multirow[t]{2}{*}{ In w-right } & Between Groups & .295 & 2 & .147 & 2.144 & .142 \\
\hline & Within Groups & 1.445 & 21 & .069 & & \\
\hline \multirow[t]{2}{*}{ In w-left } & Between Groups & .209 & 2 & .105 & 2.724 & .089 \\
\hline & Within Groups & .807 & 21 & .038 & & \\
\hline
\end{tabular}

$\mathrm{INW}=$ Intercondylar Notch width

There was no significant association between knee injuries and each of the anatomical factors Qangle $(\mathrm{p}=0.74)$, pelvic width $(\mathrm{p}=0.34)$ and IN (right and left respectively) $(\mathrm{p}=0.142 \& \mathrm{p}=0.089)$

\section{Discussions}

This study sought to establish the association between knee injuries and each of the three anatomical factors of QA, PW and INW. Q-angles ranged between $14^{\circ}$ to $18^{0}$ for both injured and non injured groups. No significant association between Q-angle and knee injuries ( $p$-value $=0.74$ ) was found in this study. This finding agrees with those of Loudon et $\mathrm{al}^{26}$, who reported no clear link between knee injuries and Qangle. Until recently, it was believed that the joint hyper laxity predisposes individuals to musculoligamentous lesions, particularly in both ankle and knee, suggesting that increase of flexibility leads to increases laxity, which perhaps, increases the incident of knee injuries for both genders ${ }^{31}$.

There were similarities in the three anatomical risk factors in both the injured and non injured groups. This findings contradicts those of Emami et $\mathrm{al}^{29}$ and Tallay et $\mathrm{al}^{32}$ found a significant association between higher Q-angle and the rate of knee injuries. However, higher QA alone might not be responsible for knee injuries as revealed by Emami et $\mathrm{al}^{29}$ who found that $16 \%$ of the males and $20 \%$ of the females with abnormally high QA did not present with knee injuries.

PW ranged between $24-29 \mathrm{~cm}$ for both injured and non injured groups with no significant association between PW and knee injuries $(\mathrm{P}=0.34)$. This finding is at variance with those of previous authors ${ }^{16,19,32,33}$ who found a significant association between PW and the risk of knee injuries amongst women. Ireland et $\mathrm{al}^{16}$, and Hirst et $\mathrm{al}^{34}$, opined that the structural differences of the wider female pelvis increases the risk of knee injury by creating a greater coxa Vara/ geno valgum alignment with concurrent increase in tibio-femoral rotation force, thus imposing greater stress on the ACL.

The present study revealed scattered INW values of between $1.3 \mathrm{~mm}$ to $2.8 \mathrm{~mm}$ for the right and $1.4 \mathrm{~mm}$ to $2.5 \mathrm{~mm}$ for the left notch for the injured group, while the values for the right and left of the non injured group were between $1.7 \mathrm{~mm}$ to $2.1 \mathrm{~mm}$ and $1.8 \mathrm{~mm}$ to $2.1 \mathrm{~mm}$, respectively. No significant association between knee injuries and INW ( $p$-values of the right and left were $p=0.14$ and $\mathrm{p}=0.89$, respectively) was found. Though, there was no attempt to compare INW with those of the male counterparts in this study, some other factors such as the differences in the ligamentous width geometry and materials of the ACL between genders might be linked to knee injuries ${ }^{35,36}$. It is therefore recommended that this should be further investigated.

A possible limitation in this study is the relatively small sample size and unequal sizes in all the groups. This might affect the generalization of the outcome to a larger population. Following a larger group for a longer period of time may produce a more generalisable outcome. Another possible factor that might affect the result of this study is participants' bias in recalling actual injury dates and time. This might have influenced the link between anatomical factors and the presence and /or absence of knee injuries. 


\section{Conclusion}

Further studies should consider documenting only knee injuries identified by team doctors or physiotherapists during the season and not those that are obtained prospectively from the players. These knee injuries might also be identified pre-seasonally by performing standardized screening tests.

\section{References}

1.Strong WB, Malina RM, Blimkie CJ, et al. Evidence based physical activity for school- age youth. The journal of Pediatrics .2005; 146:732-737.

2. Majewski M, Habelt S, Klaus S. In Epidemiology of athletic knee injuries. The knee. 2006; 13: 184188.

3. Caspersen C, Powell KE, Christenson GM. Physical Activity, exercise and physical fitness: definitions and distinctions for bealth related research .1985; 100:126-130.

4. Mandelbaum BR, Putukian M. In Medical concern and specification in female soccer players. Science and sport.1999; 14: 254-60.

5. Junge A, Dvorak J. Injuries in female football players in top-level international tournaments. British Journal of Sport Medicine. 2007; 41(suppl):P1136.

6. South Africa Football Association (SAFA) 2006.Women football in South Africa. Web site, www.SAFA.co.za

7. Pollard CD, Davis IM, Hamill J.Influence of gender on hip and knee mechanics during a randomly cued cutting manoeuver. Clinical Biomechanics. 2004;19: 1022-1031.

8. McAlindon R ACL Injuries in Women. Hughston sport medicine foundation. 1999; 11: 12-5.

9. Ireland ML, Otto SM. Special concerns of the female athlete. Clinical Sport Medicine. 2004; 23:281298.

10. Arendt E, Dick R. Knee injury pattern among men and women in collegiate basketball and soccer. American Journal of Sport Medicine. 1995; 23:694-701.

11. Steinacker T, Steuer M, Holtke V. Injuries and overload-damages at players of the German lady-soccer-national-team..Sportverletz Sportschaden. 2005;19:33-36.

12. Hewett TE, Myer GD, Ford KR. Decrease in neuromuscular control about the knee with maturation in female athletes. Journal of Bone Joint Surgery. 2004; 86-A: 1601-1608.

13. Austermuehle PD. Common knee injuries in primary care. Nurse Practitioner. 2001; 26: 6-41.
14. Souryal TO, Freeman TR. Intercondylar notch size and anterior cruciate ligament injuries in athletes: a prospective study. American Journal of Sports Medicine. 1993; 21:535-539.

15. Tilton B. Imagine a big hinge. Backpacker. 1998; 12:26-30.

16. Ireland ML. Anterior Cruciate ligament Injury in female Athlete: Epidemiology .Journal of Athletic Training. 1999; 34: 150-154.

17. Giza E, Mithofer K, Farrell L et al. Injuries in women's professional soccer. British Journal of Sport Medicine. 2005. 39:212-6

18. Stephanie LS. Anterior Cruciate Ligament Injuries in Female Soccer Players. Hughston Sport Medicine. 2002; 14: 2-3.

19. Ireland ML. The female ACL: Why is it more prone to injury? Orthopeidic Clinic North America. 2002; 33: 637-42.

20. Hahn T, Foklspang A. The Q-angle and sport. Scandinavian journal of medical science of sports.1997; 7, 43-48.

21. Horton MG, Hall TL. Quadriceps femoris muscle angle: normal values and relationships with gender and selected skeletal measures. Physical therapy. 1989; 69:897-901.

22. Li G, DeFrate LE, Zayontz S, et al. The effect of tibio-femoral joint kinematics on patellofemoral contact pressures under simulated muscle loads. Journal of orthopedic Research. 2004; 22: 801-806.

23. Lewis L. Anterior Cruciate Ligament Injury in Female athlete: Why women are so vulnerable? Literature review. Physiotherapy. 2000; 86: 464-472.

24. LaPrade RF, Burnett QM. Femoral Intercondylar notch stenosis and correlation to anterior cruciate ligament injuries: a prospective study. American Journal of Sports Medicine.1994; 22:198-203.

25. Souryal TO, Moore HA, Evans JP. Bilaterality in anterior cruciate ligament injuries: Associated intercondylar notch stenosis. American Journal of Sports Medicine. 1988; 16:449

26. Loudon JK, Jenkins W, Loudon KL. The relationship between static posture and ACL injuries in female athletes. Journal of Orthopedic and Sports Physical Therapy.1996; 24: 91-97.

27. Teitz CC, Lind BK, Sacks BM. Symmetry of the femoral notch width index; American journal of sports Medicine. 1997; 25:687-600.

28. Shelbourne KD, Facibene WA, Hunt JJ. Radiographic and intraoperative intercondylar notch width measurements in men and women with unilateral and bilateral anterior cruciate 
ligament tears. Knee Surg Sports Traumatol Atrbrosc1997. 5:229-233.

29. Emami MJ, Ghahramani MH, Abdinejad F, et al. Q-angle: An Invaluable Parameter for Evaluation of Anterior Knee Pain. Archives of Iranian Medicine 2007. 10: 24 - 26.

30. Smith TO, Hunt NJ, Donell ST. The reliability and validity of the Q-angle; a systematic review. Knee Surg Sports Traumatol Atrbrosc 2008. 16:10681079.

31. Brannan MS, Tori L, Schulthies SS, et al. A comparison of anterior knee laxity in female intercollegiate to normal population American Journal of Athletic Training. 1995 ; 30: 298-301.

32. Tallay A, Kynsburg A, Toth S, et al. Prevalence of patellofemoral pain syndrome. Evaluation of the role of biomechanical malalignments and the role of sport activity. Hungarian Orvosi Hetilap. 2004; 145: 2093 - 2101.
33. Moeller JL, Lamb MM. Anterior cruciate ligament injuries in female athlete: Why are women more susceptible? The physician and sportsmedicine. 1997; 25(4).1-10

34. Hirst HE, Armaeue E, Parsh T. Recognizing ACL tear in female athlete. What every primary care practitioner should know. The International journal of Allied Health Science and practice. 2007;5:169-203

35. Shelbuorne kD, Davis TJ, klootwykTE. The relation between the Intercondylar notch width of the femur and the incedance of ACL tears. Retrieved jan23, 2005, American Journal of Sport Medicine. 1998;26:402.

36. Renstrom P, Ljungqvist A, Arendt E, et al. Noncontact ACL injuries in female athletes: an International Olympic Committee current concepts statement. British Journal of Sports Medicine. 2008;42:394-412. 